\title{
RECYCLE: DARI SAMPAH MENJADI BUNYI (KAJIAN PENCIPTAAN MUSIK KELOMPOK WAYANGSAMPAH DI SURAKARTA)
}

\author{
Dony Setyawan \\ Pengkajian Seni Musik Pascasarjana \\ Institut Seni Indonesia Surakarta \\ Email : donsetyawan11@gmail.com|081333510840
}

\begin{abstract}
The Wayang Sampah ('trash puppet') group gives a new breakthrough inthe world of music and puppetry, as the sound phenomena that emergefrom musical instruments made from waste raw material, as well as theorganological and visual engineering of the waste become interestingreasons to study. The community's inclination towards environmental issues becomes the main characteristic of the Wayang Sampah. The breakthrougho+ered is that the music must be sounded and that it must contain an environmental message for the public. For such cause, in their shows, theWayang Sampah always carry a message to save the environment from thedangers of poorly managed garbage. Second, the music used to accompanythe Wayang Sampah performance contains a composition that supports popmusic and tradition. Music is not always about the quality of sound and theconcept of music, but the breakthrough of medium sound is also animportant aspect in the world of music debate. The creativity of Toni Kondein manipulating the organology of waste or used goods is a breakthrough inthe world of recycling. Waste can create artistic sound with good musicalorganology engineering system. Third, this achievement in soundengineering leads to the compository process for new musical garaps. Themusical works presented in Wayang Sampah are works by Wahyu Tuwek.In their performance, Sojazz musicians perform musical interactions amongthe musicians in two forms of process. Gesture interactions include eyecontact, hand code, head jerking, lip reading and overall body postureapplied as cues while improvising. The second form of the process isthrough the musical interaction itself such as accompaniment, melodicphrase and rhythmic motif, tension growth, and trade four. The process ofmusical interaction applied by Sojazz musicians as mentioned above isthrough gesture used to create mutual interaction between musicians.
\end{abstract}

Keywords: Recycle Music, Wayang Sampah, trash puppet.

\section{Pendahuluan}

Wayang Sampah adalah kelompok kesenian wayang asal Surakarta, yang menyuguhkan seni wayang alternatif, yaitu dengan menggunakan boneka wayang golek dan alat musik berbahan baku sampah. Kelompok ini dinisiasi oleh Toni Konde, Wahyu, Jumari serta Denok pada tahun 2013 silam. Empat muda mudi tersebut, menggagas kesenian tersebut dengan maksud mengurangi polusi sampah yang semakin tidak terkendali. Selain itu juga berupaya untuk memberikan edukasi kepada masyarakat tentang pentingnya pengendalian sampah agar lingkungan terjaga dari polusi sampah. Upaya ini disambut baik oleh teman-teman yang lain, hingga akhirnya terbentuklah kelompok Wayang Sampah. Toni Konde menuturkan bahwa Wayang Sampah adalah wujud keprihatinannya dan teman-teman, melihat sampah yang tidak terkendali dan semakin menumpuk. Oleh karena itu, kami berfikir untuk memberikan edukasi kepada masyarakat lewat seni, tentang pentingnya mengelola 
sampah. Dengan menumbuhkan kesadaran masayarakat tentang pengelolaan sampah, perlahan akan mengurangi kuantitas sampah di lingkungan masyarakat" (wawancara Toni Konde, 5 Desember 2017).

Toni Konde adalah seorang pecinta alam dan tergabung dalam komunitas Anak Gunung Lawu (AGL). Nalurinya tentang peduli alam sedikit banyak diperoleh dari komunitas AGL. Dari situlah kemudian mendorong dirinya untuk menggagas kelompok Wayang Sampah. Kegelisahan itu, berlanjut di dalam obrolan dengan temanteman senimannya, yaitu Jumari, Wahyu dan Denok. Ketiga teman sejawatnya itu juga merasakan hal yang sama tentang sampah yang semakin menggunung. Kegelisahan tersebut akhirnya menjadi masalah bersama yang kemudian melatarbelakangi lahirnya kesenian Wayang Sampah.

Kegelisahan itu akhirnya tidak berhenti sampai pada niat baik, tetapi sudah seperti panggilan jiwa, yang secara otomatis menjadi bagian dari hidup tentang peduli terhadap lingkungan. Lewat kelompok Wayang Sampah mereka gunakan sebagai jalan atau akses untuk menumbuhkan kesadaran masyarakat tentang pengelolaan sampah. Denok juga menuturkan bahwa Wayang Sampah baginya sudah seperti bagian dari hidup atau panggilan jiwa untuk membuat seni pertunjukan dengan model tutur yang berkisah tentang bahan sampah jika tidak dikelola. Tidak hanya pentas, tetapi juga memberikan workshop tentang daur ulang sampah menjadi benda seni dan bernilai jual" (wawancara Denok, 28 Desember 2017).

Selain itu, harapannya Wayang Sampah tidak hanya menjadi media tutur terhadap edukasi tentang pengelolaan sampah. Lebih dari itu masyarakat mampu menjadi agen perubahan terhadap lingkungan yang semakin hari semakin tercemar terhadap sampah. Semakin banyak agen perubahan, semakin memperluas jaringan masyarakat peduli terhadap lingkungan.

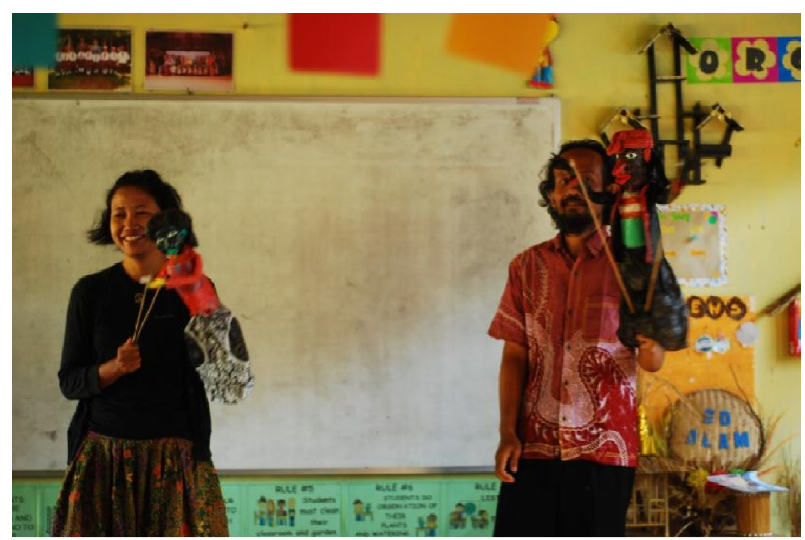

Gambar 1. Dari kiri Denok, Toni Konde, saat memberikan workshop pembuatan Wayang Sampah.

(Foto: Dokumen Wayang Sampah, 2017).

Debutnya sebagai kelompok seni, Wayang Sampah telah banyak mewarnai pergelaran seni di dalam maupun di luar Kota Solo. Pertama pentas dalam acara Hari Teater Dunia (HATEDU) yang ke I pada tahun 2014. Kemudian pentasnya berlanjut dalam acara Grebeg Sudiro dalam rangka perayaan Imlek di Surakarta tahun 2014. Wayang Sampah juga beberapa kali diundang dalam pentas sekaligus workshop di Bandung dalam rangka Hari Peduli Sampah Nasional pada tahun 2015.

Format Wayang Sampah saat pertama kali muncul, menggunakan musik dengan medium musik Barat, belum menggunakan bahan sampah, yaitu: musik beraliran blues dengan menggunakan medium bunyi gitar elektrik, bass elektrik, vokal, kajon, serta biola. Format tersebut berlangsung selama kurang lebih 4 tahun. Lagu-lagu yang dibawakan adalah lagu-lagu populer bergenre pop, blues, rock, dan kadang juga membawakan lagu-lagu tradisi Jawa karya Nartosabdo.

Dalam perkembangannya, pada akhir tahun 2016 muncul pemikiran tentang alat musik yang diproduksi dari bahan sampah. Agar performanya tentang demonstrasi peduli sampah semakin meyakinan, akhirnya diputuskan untuk membuat alat musik dengan bahan baku sampah, seperti sampah kaca, besi, peralon, ember bekas, serta kaleng bekas, dan lain sebagainya. 
Upaya pembuatan alat musik dari sampah tersebut, semata-mata hanya untuk memenuhi koherenitas antara bunyi dan sumber bunyi. Jika bunyi musiknya menyuarakan tentang pengelolaan sampah, sumber bunyinya juga harus bersumber dari sampah yang sudah di-recycle. Pembuatan alat musik ini, lebih menekankan pada aspek relasi logis antara misi dengan fisik yang digunakan, bukan sebagai kebutuhan bunyi. Kalau dalam rangka menempuh kebutuhan bunyi, alat musik konvensional bisa digunakan. Kendati demikian, bukan berarti bunyi dalam perangkat alat musik daurulang tersebut tidak memilikiartistik atau nilai bunyiyang khas, justru sisi lain yang kami ingin capai adalah alat musik dari bahan sampah yang secara estetika bunyi memiliki kekhasan suara, dan memiliki khas bentuk dan bahan. Sehingga musik yang disusun menjadi memiliki nilai komposisi yang baik (wawancara Toni Konde, 20 Januari 2018).

Penjelasan di atas menandai bahwa, keberadaan Wayang Sampah tidak hanya berjuang terhadap sampah semata, tetapi juga berupaya menciptaakan seni dengan medium yang baru, yaitu medium bunyi dari bahan baku sampah. Secara model penciptaan medium bunyi, ini adalah suatu upaya yang cukup baik dan perlu mendapatkan apresiasi dari para kreator musik, utamanya dalam bidang organologi musik. Dari pemikiran tentang lingkungan hingga sampai pada memproduksi alat musik baru, adalah langkah kerja yang memiliki nilai moral dan nilai artistik. Hal itu memberikan pemahaman bahwa, sumber bunyi musik bisa dicipta dari apapun, termasuk benda di sekitar kita.

Kemampuan mencipta alat musik tersebut tentu tidak setiap orang dapat melakukannya. Pengalamannya terhadap bunyi musik dan kiprahnya dalam musik sudah tentu menjadi modal utama dalam menempuh kerja cipta alat musik tersebut. Seperti yang telah dipaparkan di atas, banyak keterlibatan seniman musik dan wayang dalam kelompok ini. Sudah barang tentu mereka mempengaruhi dalam proses pembuatan alat musik tersebut. di antaranya ada Wahyu, dia adalah musisi yang cukup senior di wilayah Solo, dan dikenal sebagai musisi balada. Berikutnya ada Gardian Nusantara, musisi sekaligus alumni Jurusan etnomusikologi ISI Surakarta, yang secara kompetensi cukup baik dalam menguasai organologimusik.

\section{Semangat Merawat Lingkungan}

Selain berkesenian, ruh dari kelompok Wayang Sampah dengan kepeduliannya pada isu lingkungan. Misi kemanusiaan tersebut selalu menjadi wacana yang utama saat gelaran pertunjukan Wayang Sampah. Kelompok tersebut memiliki jargon untuk mengenalkan 3R yaitu reduce, reuse dan recycle sampah. Reduce adalah upaya untuk mengurangi timbunan-timbunan sampah di lingkungan masyarakat sekitar, dengan adanya upaya pencegahan tersebut maka penumpukan sampah tidak akan terjadi. Reuse adalah menggunakan kembali sampah atau bahan-bahan yang terbuang dan tidak terpakai agar tidak terjadi penumpukan sampah di lingkungan sekitar kita. Recycle adalah kegiatan daur ulang sampah, yang kemudian diolah kembali menjadi barang atau kerajinan yang memiliki nilai jual atau manfaat.

Hal ini menjadi latar belakang yang kuat tentang bagaimana instrument tersebut diproduksi, bahwa setiap seniman mencipta tidak sekedar melampiaskan keinginan estetisnya, tetapi oleh sebagian entitas yang berasal dari lingkungan hidupnya. Entitas itu yang lantas membuatnya sesak, membuatnya gelisah dan kemudian berucap. Dan, karena jiwanya gatal, ia menggaruknya lewat karya seni. Selanjutnya digoreskan melalui produk seni (Sumardjo, 2000:86).

Wayang Sampah tidak hanya sebagai hiburan yang memiliki nilai artistik, akan tetapi juga rangka menempuh kesadaran masyarakat atas pentingnya mengelola sampah, dan sadar akan lingkungan yang bersih. Oleh karena itu, kelompok Wayang Sampah dalam menebarkan semangat konservasi lingkungan tidak berhenti sampai pada pertunjukan seni, akan tetapi juga menempuh jalurjalur edukasi lewat workshop. Sasaran kegiatan workshop kelompok Wayang Sampah adalah generasi muda mudi. Selama ini yang mendominasi peserta workshop adalah anak-anak. Karena lewat 
anak-anaklah masa depan lingkungan dapat dijaga dengan baik.

Produk daur ulang yang dilakukan memiliki ciri yang spesifik dari pada aktivis lingkungan yang lain, jika yang lain menciptakan produk mengolah sampah menjadi barang bernilai jual seperti: kerajinan tas, baju, serta hiasan dinding dan lain sebagainya. Wayang Sampah membuat produk olahan sampah menjadi barang-barang bernilai artistik dan tentu juga memliki nilai jual, seperti pembuatan boneka wayang dan alat-alat musik. Hal ini dianggap lebih menarik perhatian karena memuat aspek hiburan dan kreativitas, karena seni memiliki dimensi keindahan yang semua orang dapat menikmatinya.

\section{Proses Penciptaan Musik Wayang Sampah}

Ide besar penciptaan musik Wayang Sampah diawali dari pemikiran Konde bersama teman-teman Anak Gunung Lawu (AGL) melihat sampah-sampah yang makin lama makin menumpuk. Kegelisahan itu mengundang beberapa pemikiran salah satunya adalah melakukan daur ulang. Tidak pernah terbayangkan sebelumnya akan didaur ulang menjadi sebuah alat musik. Melalui tangan kreatif Konde, sampah atau barang-barang bekas rumah tangga diinovasi menjadi instrumen musik.

Sebelumnya Konde memang sudah memiliki komunitas yang peduli dengan sampah, yakni dengan mendaur sampah menjadi boneka wayang. Kepedulian terhadap limbah bekas dan jiwa kesenimanannya memberikan sumbangsih banyak tentang lahirnya alat-alat musik daur ulang yang diprakarsai oleh Konde dan teman-teman. Keberpihakannya terhadap daur ulang sampah sangat bertendensikepada penyelamatan lingkungan. Mendaur ulang menjadi alat musik, bukan hanya sekedar terobosan ide, namun juga berkelanjutan sebagai upaya edukasi kepada masyarakat tentang pentingnya mengelola sampah menjadi produk lain, agar sampah-sampah di lingkungan menjadi berkurang.

Kegemaran Konde mengeksplorasi sampah sebetulnya sudah tampak saat dia menginisiasi pembuatan wayang dari sampah plastik dan kertas. Ide itu menunjukan keberpihakan Konde terdahap lingkungan. Itu adalah tonggak awal ide penciptaan alat musik dari sampah ini. Pergerakan Konde memang tidak sendirian, di sekitarnya terdapat beberapa teman seniman yang membantu dirinya dalam bermusik, seperti Wahyu, Eko Aprianto, Gardian Nusantara, Nanang, serta Denok. Temanteman tersebut yang membantu konde dalam menuangkan ide dalam wujud karya musik.

\section{Lorong-lorong Mencipta Musik}

Musik dapat dicipta melalui dorongan atau sumber apapun. Banyak hal yang mempengaruhi lahirnya sebuah musik dilatarbelakangi berbagai macam dalih. Ada yang mencipta didasari atas fenomena, ada yang mencipta didasari atas masalahmasalah sosial, ada yang mencipta lantaran pengalaman hidup, dan masih banyak lagi. Loronglorong penciptaan musik itu seperti memiliki sumber dan muaranya sendiri. Sadra dalam tulisannya menjelaskan bahwa.

"Mencipta barangkali tidak dapat dilepaskan dari suatu kepentingan tertentu. Untuk apa karya musik itu diciptakan... suatu penciptaan dan penyajian musik sesungguhnya tidak dapat dihindari dari "dalam rangka" mencipta pada dasarnya adalah kontekstual. Makna kontekstual di sini tidak sekedar gambaran hubungan dan kepentingan-kepentingan yang ada di luar wilayah pribadi kreator"' (Sadra, 2005: 78).

Pernyataan Sadra di atas, menegaskan bahwa, musik dicipta selalu memiliki tendesi yang melingkupinya. Nilainya bukan lagi persoalan kualitas bunyi, bagaimana struktur bunyi itu bekerja, kualitas artistik apa yang ditawarkan, serta kerumitan matematis apa yang dipraktikan. Jauh di luar masalah itu, tersemat banyak kepentingan, seperti: dalam rangka apa musik, tersebut dicipta, pesan apa yang disampaikan, sejauh mana urgensi musik tersebut dicipta. Lorong-lorong itu lantas menjadi fondasi 
penting dalam proses mencipta musik. Salah satunya adalah musik wayang sampah yang diinisiasi oleh Konde.

Dilatarbelakangi oleh keberadaan sampah yang memasuki tahap yang memprihatinkan. Kepedulian masayarakat terhadap sampah yang mulai terkikis, membuat dirinya dan teman-teman merasa gelisah dan harus melakukan sesuatu. Kegelisahan tersebut melatari berbagai macam ide dan aplikatifnya. Agar ide dapat dituangkan menjadi produk yang lantas dapat diapresiasi masyarakat berbagai lapisan, dipilihlah seni, khususnya musik dan wayang sebagai media menuangkan ide.

\section{Peduli Lingkungan}

Dilatarbelakangi oleh keterlibatannya Konde dalam komunitas pecinta alam. Kiprahnya sebagai Anak Gunung Lawu (AGL), membuat dia akrab dengan alam dan kondisi lingkungan. Konsep tentang mencintai lingkungan didapat dari dialektika dalam komunitas AGL tersebut. Kecintaannya terhadap alam, mendorong dirinya untuk melakukan sesuatu, salah satunya dengan daur ulang sampah. Alih-alih berniat mengelola sampah, nyatanya menjadi titik awal dirinya berkiprah di dunia seni musik. Konsep penyelamatan lingkungan tersebutlah yang hingga kini menjadi konsen Konde dalam bermusik. Jadi, aktivitasnya bersama komunitas Wayang Sampah tidak didasari atas motif ekonomi atau apapun. Gerakan yang diinisasi murni tentang lingkungan dan kemanusiaan.

Misi tersebut lantas mendapat dukungan dari berbagai teman seniman. Terdapat beberapa musisi yang kemudian bergabung dan menjadi pilar penting di dalam kreativitas mencipta musik di Wayang Sampah. Pertama ada Wahyu Tuwek, alumni etnomusikologi yang cukup ulung menjadi seniman balada. Kedua, Gardian Nusantara, alumni Jurusan etnomusikologi ISI Surakarta yang malang melintang sebagai praktisi musik tradisimaupun kontemporer. Ketiga ada Denok, seorang guru sekolah dasar sekaligus aktivis pencinta lingkungan. Keempat adalah Dora, seorang darmasiswa ISI Surakarta dari Hungaria. Kempat adalah Nanang mahasiswa
Jurusan Etnomusikologi ISI Surakarta yang juga seorang kreator musik eskperimental. Keenam ada Rendy pengrajin gitar yang juga teman baik dari Konde.

Pertemuannya dengan para musisi membantu Konde dalam menuangkan gagasan lingkungannya melalui komposisi musik. Konde berada dalam ranah kontekstual sementara temantemannya berada dalam wilayah tekstual. Komposisi peranan tersebut membuat komunitas Wayang Sampah menjadi lengkap. Ada sang kreator ide dan instrumen, dan ada yang menjadi kreator musik. Kedua wilayah tersebut lantas menjadi kekuatan Wayang Sampah. Keberadaannya sebagai komunitas seni, tidak hanya sebatas berkarya, tetapi juga memberikan edukasi dan wawasan kepada masyarakat terkait dengan etika lingkungan.

Keberpihakan ide Konde dan kawankawan juga menjadi keberpihakan esensi musik yang tengah dicipta. Medium bunyi yang digunakan merupakan daur ulang sampah yang diformulasikan ulang menjadi alat musik. Misi yang dibawa Wayang Sampah, tertuang kepada bahan alat berkeseniannya dan teks vokalnya. Secara musikal, komposisi yang disusun merupakan komposisi dengan pendekatan musik kontemporer. Tidak ada kekhususan bunyi yang dicipta untuk menyuarakan lingkungan. Nilai yang menarik dari komunitas ini adalah terobosan musikal dalam konteks medium bunyinya.

Umumnya terobosan daur ulang limbah menjadi alat musik, terjadi dari sampah menuju alat musik perkusif. Karena itu merupakan daur ulang yang sederhana, seperti kaleng bekas, ember bekas, dan botol-botol bekas. Berbeda dengan alat musik yang digunakan oleh Wayang Sampah. Sampah bekas rumah tangga diubah menjadi alat musik perkusif, upaya rekayasa oranologinya hampir tidak ada. Sementara dalam ragam alat musik Wayang Sampah, memiliki kerumitan tersendiri, lantaran diperlukan rekayasa organologi sehingga dapat menjadi bentuk instrumen yang baru.

Di tempat lain, berlomba-lomba dalam upaya pengembangan musik dalam wilayah estetika. Tentu tidak ada yang salah, hanya saja berbeda visi dan misi. Terdapat dua wilayah besar motif 
penciptaan di dalam dunia musik. Beberapa kreator mengunggulkan wilayah kerja musikal yang bagus, seperti: jalinan bunyi, kerumitan ritmikal, hingga matematis bunyi yang kompleks. Sementara beberapa kreator mengunggulkan konsep musiknya, artinya peristiwa di balik musik tersebut menjadi hal yang utama. Kedua perspektif itu hingga kini menjadi perdebatan yang tidak pernah selesai. Menurut penulis, keduanya tidak ada yang lebih unggul atau lebih rendah. Seperti yang disampaikan Sadra sebelumnya, penciptaan musik erat kaitannya berkutat pada konsep mencipta "dalam rangka". Konsep itulah yang sebetulnya menjadi fondasi dasar penciptaan musik selama ini.

\section{Upaya Eksperimental Medium Bunyi}

Konde, konsen dalam upaya penciptaan alat musik daur ulang kurang lebih selama 3 tahun. Dia tidak hanya fokus pada eksperimental bunyi di dalam kelompok Wayang Sampah, tetapi juga dengan kelompok Limbah Berbunyi Project di Yogyakarta. Kiprahnya sebagai kreator alat musik berbahan sampah sudah di kenal di wilayah Solo dan Yogakarya. Melalui tangannya sudah tercipta lebih dari 20 alat musik baik berjenis perkusif dan melodis. Konde memiliki labortorium mini di rumahnya yang berwujud pendopo kecil. Tempat tersebut dipenuhi dengan perkakas mulai dari barang bekas, kayu, besi-besi, hingga perabot pertukangan.

“...semua alat saya kerjakan sendiri dengan keterbatasan alat-alat yang saya miliki. Ya ini tempat saya ngulik barang-barang bekas, hampir setiap hari saya mengerjakan alatalat baru. Sebagian saya kirim ke Jogja, karena saya juga tergabung dalam kelompok musik Limbah Berbunyi Project..." (wawancara, Konde 20 Juni 2018).

Jika diamati, kualitas bunyi yang dihasilkan dari alat eksperimental tersebut, memiliki kualitas bunyi yang tidak begitu sempurna. Artinya masih banyak hal yang kurang di beberapa aspek, seperti alat musik cello, kualitas tonenya belum begitu jernih, power suaraya yang lemah, dan bentuk alat musiknya yang kurang presisi. Semua diakui Konde lantaran semuanya berbahan baku barang-barang sampah. Selain itu, alat musik tersebut dibuat bukan untuk kepentingan industrial, jadi kepentingan kualitas bukan menjadi prioritas.

“...saya bukan ahli dalam bidang organologi atau pengrajin alat musik yang baik. .. gimana lagi memang bahannya dari bahan sampah, yang penting di sini limbah tersebut berfungsi dan beralih rupa menjadi alat musik. Poin utamanya bukan kualitas suara tetapi lebih pada terobosan idenya untuk mengurangi sampah..." (wawancara, Konde 20 Juni 2018).

Pernyataan Konde di atas, menyiratkan bahwa upaya itu demi kepentingan lingkungan, lantas sejauh mana pengaruh daur ulang yang dilakukan Konde terhadap perubahan lingkungan? Kiranya pertanyaan itu menjadi ukuran suatu pergerakan sebuah misi kemanusiaan. Jika ditilik dari sisi musikal, langkah yang dilakukan Konde dan kawankawan adalah misi kesenian yang mulia. Selain melakukan trobosan alat musik, dia juga menyajikan musik dengan penuh pesan moral. Signifikasi perubahan terhadap lingkungan secara nyata tidak begitu tampak, tetapi lebih pada motif mengedukasi masyarakat lewat kesenian. Demo itu yang berusaha diupayakan untuk merubah gaya hidup masyarakat melalui kesenian yang disajikan.

Selain kerja di laboratorium mininya, eksperimental juga dilakukan lewat workshop diberbagai sekolah SD dan rumah-rumah kreatif. Hal itu menandai kerja eksperimentalnya juga berelasi dengan masyarakat. Secara implisit memeberikan tentang ilmu mendaur ulang dan pentingnya merawat lingkungan. Dua wilayah yang secara disiplin itu sudah sama sekali berbeda. Seni bermuara pada kualitas estetika dan artistik, sementara misi penyelamatan lingkungan bermuara pada aspek sosial dan lingkungan. Lewat kelompok seni Wayang Sampah, dua aspek itu menjadi satu kesatuan yang dipadu menjadi esensi seni yang ditawarkan. 


\section{Mencari Bahan}

Proses menentukan bahan dibagi menjadi beberapa kategori yaitu: bahan plastik, tembaga, kayu, dan besi. Bahan tersebut yang kemudian menentukan alat apa yang akan dibuat sesuai dengan bahan yang ada. Jenis bahan dan kualitas bahan akan menentukan jenis alat apa yang akan produksi. Jenis bahan dan volume bahan yang ada akan menentukan jenis alat apa yang akan dibuat.

Bahan plastik mudah didapatkan seperti, karung plastik. Bahan besi bisa didapatkan dari bengkel otomotif seperti per. Bahan tembaga atau seng bisa didapat dari tempat pengepul barang bekas, biasa yang digunakan adalah kaleng bekas minuman dan kaleng biskuit. Begitupun juga dengan pipa peralon bekas, mudah didapatkan dari beberapa pengepul barang-barang bekas. Kemudian kaca bekas yang dipilih adalah kaca untuk keperluan furniture atau mebel. Bahan yang lain adalah kawat bekas, drum bekas, kayu, dan lain sebagainya bisa didapat di tempat loak barang bekas.

Di pasar loak berupa paralon bekas, drum bekas, kawat bekas. dari sampah rumah tangga berupa kantong plastik, botol-botol plastik air mineral, karung plastik bekas beras atau bekas karung pupuk. dari sampah bangunan berupa kayukayu bekas, besi-besi bekas. Menurut Konde, pencarian bahan-bahan untuk keperluan membuat alat musik tidaklah sulit. Dia sering mendapatkan barang-barang bekas dari tukang loak dan pengepul barang-barang bekas.

“...barang itu ada di sekitar kita, beberapa memang saya dapatkan dari tukang loak dan pengepul rongsokan. Saya pilih yang dapat digunakan menjadi bahan baku, apapun itu baik kaca, blek bekas, kaleng, besi-besi dan peralon-peralon.., tetapi kadang juga mengumpulkan sendiri”' (wawancara, Toni Konde 26 Juli 2018).

\section{Mengolah Bahan}

Toni Konde, tidak pernah belajar tentang ilmu organologi sebelumnya. Dia mengerjakan pembuatan tersebut dengan cara eksperimental seorang diri, dengan cara mengamatialat-alat musik yang sudah ada. Proses pembuatan alat-alat tersebut dilakukannya seorang diri di pendopo kecil miliknya. Dia juga bukan merupakan pemusik yang baik, atau bahkan seorang komposer. Kecintaannya terhadap musik ia dapatkan dari temannya, yaitu Wahyu Tuwek, yang kebetulan di dalam kelompok Wayang Sampah merupakan seorang komposer. Toni dalam wawancaranya juga mengatakan bahwa ia hanya suka bermusik, belajar membuat alat musik dari bahan bekas ini secara otodidak. "Aku dudu wong sing pinter bermusik, opo maneh gawe karya (saya bukan seseorang yang mahir bermusik, apalagi berkarya) saya jauh dari itu, karena Mas Wahyu saya kenal dengan musik, lantaran setiap hari dia menggeluti dunia musik, dan kebetulan kuliah etnomusikologi di ISI (Institut Seni Indonesia) (wawancara, Konde 20 Juli 2018).

Pernyataan Konde di atas, menggaris bawahi bahwa, kecintaannya terhadap senilah yang membuat dirinya secara otodidak dapat membuat rekayasa organologi barang-barang sampah. Kini, ia sudah memproduksi puluhan alat musik baik itu alat melodi dan perkusif. Karyanya sudah dikenal seniman sepanjang Solo dan Yogyakarta.

\section{Bahan Plastik}

Bahan plastik adalah bahan yang paling mudah dijumpai. Nyaris setiap aktivitas manusia sehari-hari bersinggungan dengan plastik, oleh karenanya, plastik adalah masalah utama di bumi ini yang harus didaur ulang menjadi produk seni atau kerajian. Bahan plastik adalah kantong plastik, pipa plastik tak terpakai, ember plastik dan masih banyak lagi. Bahan kantong plastik biasa diubah menjadi boneka wayang, ada juga yang digunakan sebagai membran alat musik. Pipa plastik bisa dijadikan badan atau resonator sebagai kendang atau alat perkusif lainnya. Selain itu juga bisa dijadikan alat musik tiup seperti seruling. Sampah plastik dirasa bahan baku paling mudah didapat dan paling mudah diubah menjadialat musik. 


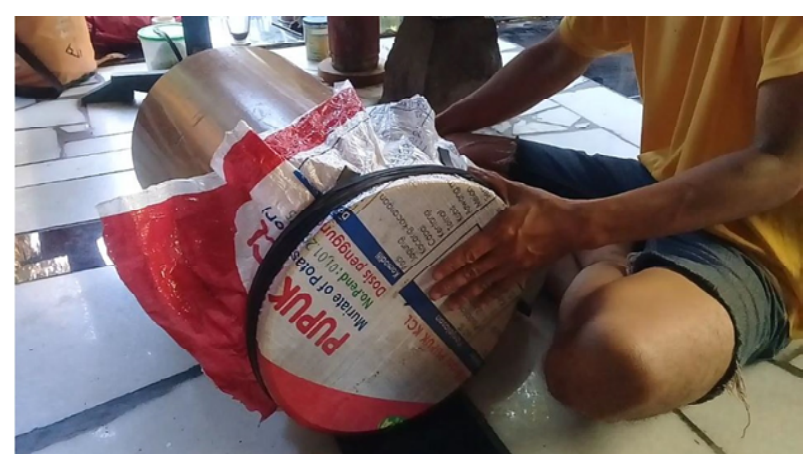

Gambar 2. Gendang peralon bermembran karung pupuk plastik. (Foto: Dony Setyawan, 2018).

Alat musik di atas terbuat dari bahan baku pipa pvc, atau peralon yang besar ukuran 12 inchi dengan membran menggunakan karung pupuk plastik. Cara memainkannya dengan cara dipukul menggunakan telapak tangan seperti memainkan alat musik kendang pada umumnya. Alat musik kendang di atas bermembran satu muka. Karakter suara yang dihasilkan adalah suara low. Karena menggunakan membran dari plastik, bunyinya tidak memiliki sustain seperti kendang yang terbuat darikulit atau mika. Suaranya dapat berkarakter low lantaran resonatornya memiliki ukuran yang cukup besar dan memiliki ruangan yang cukup longgar.

\section{Bahan Tembaga}

Bahan logam biasanya seperti per, dawai, serta kaleng-kaleng bekas. Bahan-bahan itu bisa digunakan utuk membuat banjo, cak, lonceng, atau sebagai resonator pada alat musik berdawai. Sampah jenis ini biasa didapatkan dari pengepul barang bekas. Jenis bahan ini juga mudah didapatkan, yang sering digunakan bahan ini biasa adalah kaleng bekas biskuit, atau kaleng bekas minuman. Secara bentuk bahan, barang-barang tersebut mudah untuk dimodifikasi menjadi alat musik, dibandingkan dengan bahan tembaga yang lainnya. Selain itu seng juga masuk dalam kategori bahan yang dieksplorasi. Dengan bahan ini bisa eksplorasi menjadi resonator gitar, ukulele, dan cello.

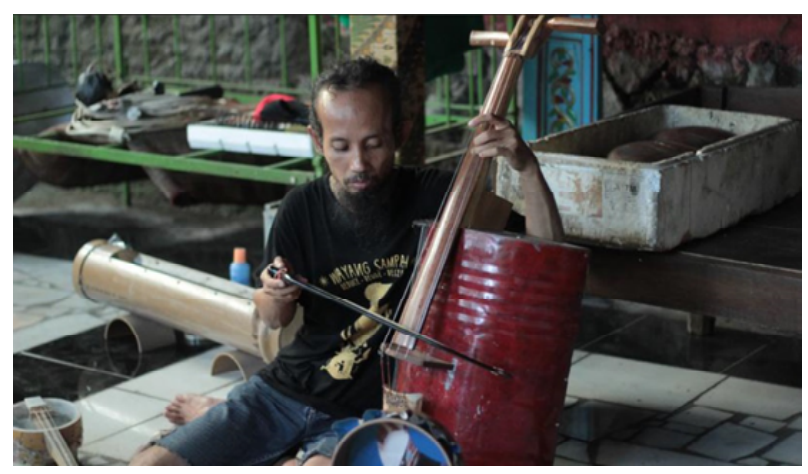

Gambar 3. Cello berbahan limbah karya Konde. (Foto: Dony Setyawan, 2018).

Alat musik di atas adalah cello berbahan baku limbah kayu dan drum. Memainkannya dengan cara digesek dengan alat gesek rebab. Cello konde merupakan alat musik gesek yang mengadopsi bentuk cello pada musik barat. perbedaan cello konde dengan cello pada umumnya adalah material bahan bakunya. Jika pada umumnya bodi cello terbuat dari kayu, material bahan bodi pada cello konde terbuat dari drum besi bekas. Alat musik ini mempunyai 4 buah senar yang dimainkan dengan cara digesek. Karakter bunyi cello konde tersebut, hampir sama seperti cello pada umumya. Tetapi terdapat sedikit nois yang timbul akibat gesekan alat geseknya dengan senar string pada cello konde sedangkan cello pada umumnya menggunakan senar nilon. Jadi gesekan pada cello konde terkesan kasar. Cello Konde memiliki warna suara low, midle, dan high.

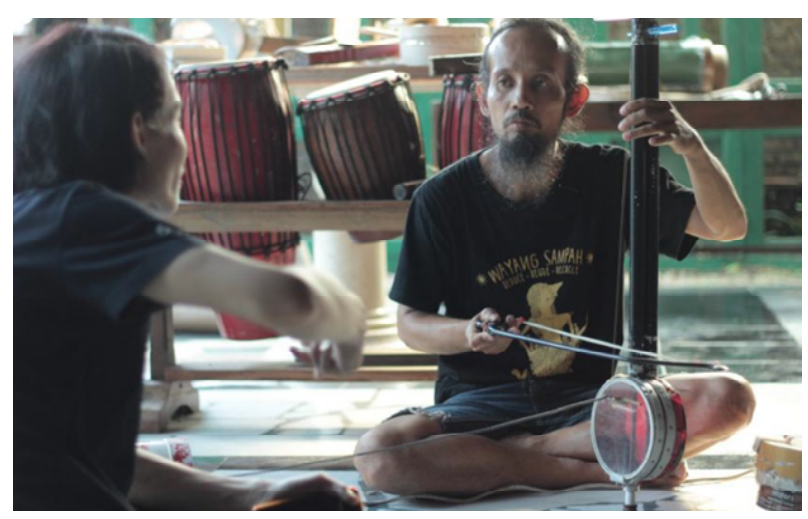

Gambar 4. Rebab dari limbah besi, mika, alumunium, serta sikat gigi. (Foto: Eko Aprianto, 2018). 
Melihat resonatornya adalah drum bekas, yang secara fisik adalah terbuat daribahan tembaga, sudah barang tentu suaranya tidak seperti cello pada umumnya. Demi kepentingan pentas, juga tidak terdapat amplifikasi secara kusus untuk dapat memperindah suara cello Konde. Instrumen di atas adalah rebab dari bahan baku pipa besi, peralon plastik, dan mika sebagai resonatornya. Cara memainkannya dengan cara digesek dengan alat gesek rebab. Dawainya menggunakan senar gitar dan menggunakan pengait atau tuningnya gagang sikat gigi. Kemudian resonatornya diberikan per memanjang, sehingga gesekan alat gesek dan dawai getarannya menyebar ke mebran dan per panjang, sehingga membuat suara menjadi khas atau unik.

Karakter suara yang dihasilkan oleh rebab konde ini. suaranya justru nyaris mirip dengan instrumen seperti tarawangsa. Bunyi rebab Konde lebih menonjol dengan suara high. Dalam permainannya juga tidak terdapat amplifikasi untuk dapat membantu memperindah atau membuat lebih nyaring suaranya.

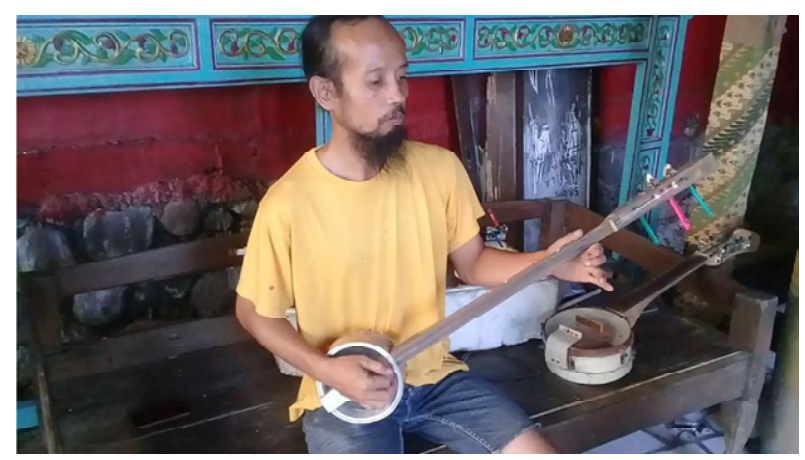

Gambar 5. Instrumen shamisen string konde. (Foto: Dony Setyawan, 2018).

Mengadopsi bentuk dari alat musik Jepang yang terdiri dari 3 senar. Shamisen string konde terbuat dari pipa paralon ukuran 6 inchi pada bodi dengan dilapisi plastik mika pada bagian depan, sedangkan pada bagian belakang ditutup kaleng biskuit berbentuk bulat yang berfungsi untuk memperkeras suara senar atau sebagai resonator. Dinamakan shamisen string karena pada umumnya shamisen di Jepang menggunakan senar berbahan baku sutra dan nilon, sedangkan shamisen string konde menggunakan senar string yang biasa digunakan pada senar gitar nomor 1,2,3.

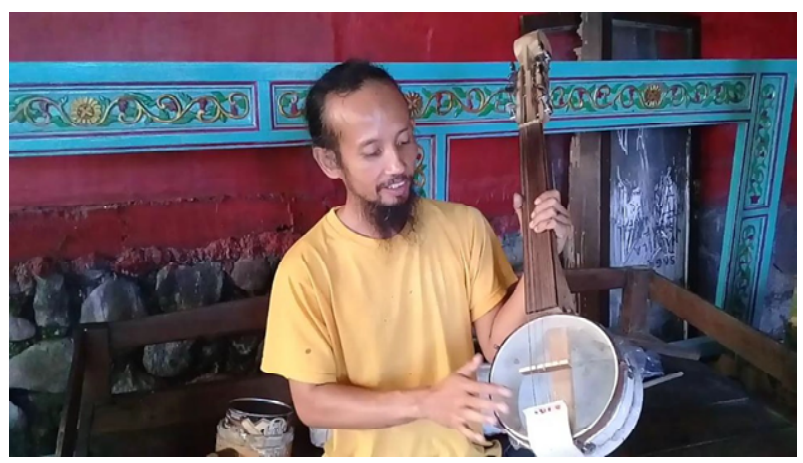

Gambar 6. Gambus konde. (Foto: Dony Setyawan, 2018).

Gambus konde mengadaptasi alat musik petik yang berasal dari Timur Tengah, yang dipasangi 3 senar sampai 12 senar. Gambus konde terbuat daripipa peralon ukuran 8 inchi. Badan instrumennya ditutup dengan plastik mika pada bagian depan dan belakang berfungsi untuk resonansi. Alat tersebut menggunakan 9 buah senar dan dimainkan dengan cara dipetik. Karakter suaranya menyerupai alat musik banjo. Namun gambus Konde tersebut sedikit lebih kasar, karena sistem organologinya yang tidak dirancang dengan baik seperti instrumen Banjo. Dalam permainannya juga tidak terdapat bantuan amplifikasi untuk membantu memperindah kualitas suara.

\section{Bahan Kaca}

Limbah kaca juga menjadi bahan eksplorasi oleh Konde. Kali ini idenya adalah membuat instrumen saron berbilah kaca bekas dan beresonator peralon bekas. Bilah-bilah kaca tersebut detuning dengan laras diatonis: do, re, mi, fa, sol, la, si. Tidak hanya itu, badan instrumen sebah kiri juga diberikan merman dari plastik, jadi juga dapat dimainkan sebagai instrument membran. Lebih dari itu alat musik tersebut bisa dimainkan secara bersamaan dengan satu pemain musik. Tangan kanan memainkan bilah-bilah kaca, dan tangan kiri memukul membran plastik. 


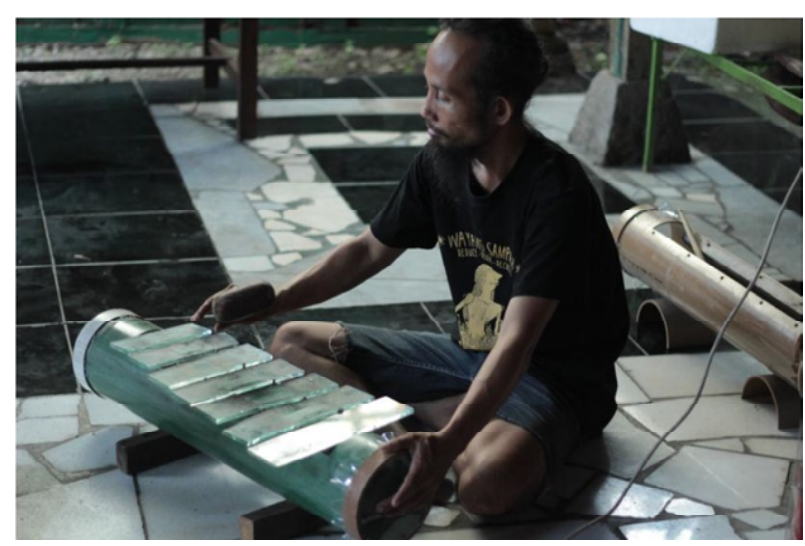

Gambar 7. Saron kaca konde. (Foto: Dony Setyawan, 2018).

Saron kaca konde adalah alat musik pukul yang mengadopsi bentuk saron pada gamelan Jawa, akan tetapi menggunakan bahan bilah dari kaca dengan ketebalan $8 \mathrm{~mm}$ dan rancakan terbuat dari pipa paralon ukuran 6 inchi. Alat ini dimainkan dengan cara ditabuh dengan menggunakan alat tabuh dari kayu sama seperti tabuh saron pada umumnya. Namun power cara menabuhnya tidak dapat sekuat seperti memukul intrumen saron yang terbuat dari logam. Karakter bunyinya tidak seperti saron yang berbahan logam. Suara yang dihasilkan oleh saron kaca ini secara kualitas suara lebih nyaring, tetapi powernya sangat lemah. Secara artikulasi bunyi juga lebih jelas, dan tidak memiliki sustain yang panjang seperti bunyi saron logam. Cara membunyikannya juga tidak harus diredam dengan tangan setelah membunyikan.

\section{Bahan Besi}

Limbah besi otomotif juga menjadi bahan ekplorasi Konde. Besi per dijadikan alat musik semacam genta, posisinya direntangkan di antara dua membran.

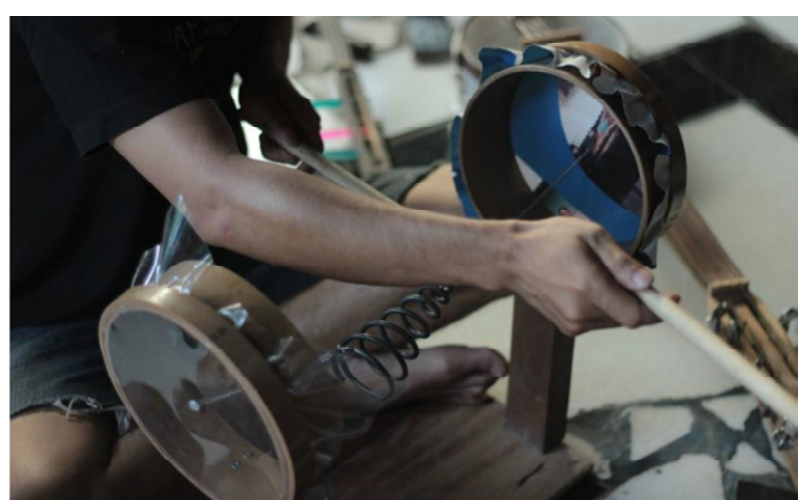

Gambar 8. Instrumen genta dari limbah per otomotif. (Foto: Dony Setyawan, 2018).

Cara membunyikannya dengan cara dipukul menggunakan stik. Karakter bunyi yang dihasilkan seperti dentuman petir yang menggelegar. Kesan suara itu dihasilkan karena logam yang dipakai adalah berbentuk per dan beresonansi mika atau plastik. Alat ini juga tidak dibantu dengan amplifikasi khusus, karena suaranya sudah cukup berkarakter sebagai efek bunyi yang khas.

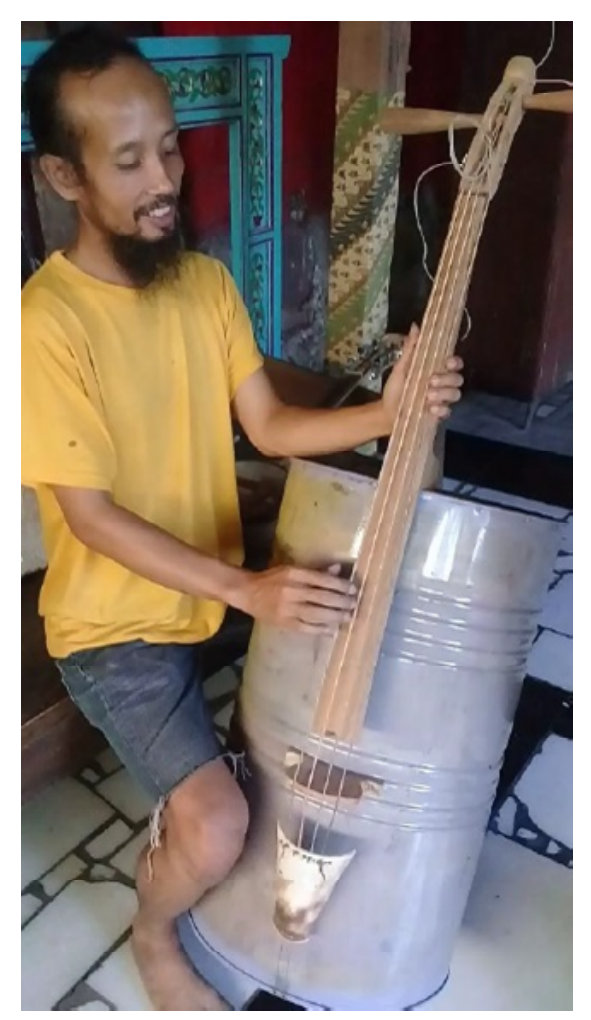

Gambar 9. Instrumen bass betot konde. (Foto: Dony Setyawan, 2018). 
Bass betot konde adalah alat musik petik yang mengadopsi bentuk bass betot atau contrabass akan tetapi bodinya terbuat dari drum besi bekas dan untuk necknya terbuat dari kayu seperti alat musik bass pada umumnya. Menggunakan 4 buah senar nilon alat musik ini dimainkan dengan cara dipetik. Karakter suara yang dihasilkan adalah berkarakter low, hampir sama dengan suara contrabass karena sama-sama menggunakan senar nilon.

\section{DAFTAR PUSTAKA}

Djohan Salim. 2009. Psikologi musik. Yogyakarta: Best Publisher.

Sadra, Wayan, I. 2005. "Lorong Kecil Menuju Susunan Musik", dalam Waridi (ed), Menimbang Pendekatan Pengkajian dan Penciptaan Musik Nusantara. Surakarta: Jurusan Karawitan STSI Press Sekolah Tingi Seni Indonesia (STSI Surakarta) hlm. 75-93.

Safira, Gloria. 2017. "Kresipah: Bermusik dengan Sampah”. Jakarta: Yayasan Kebun Raya Indonesia.
Sumardjo, Jacob. 2000. Filsafat Seni. Bandung: ITB.

Sunarto, Bambang. 2013. Epistemologi Penciptaan Seni. Yogyakarta: IDEA Sejahtera

\section{DAFTAR NARASUMBER}

Cahyati Praba Hardini (Denok) 37 tahun, musisidan pengurus Wayang Sampah. Alamat Jaten, Karanganyar.

Eko Aprianto Romadona, 29 tahun, musisi kelompok Wayang Sampah. Alamat Tasikmadu, Karanganyar.

Wahyu Sri Praptanto (Wahyu Tuwek), 41 tahun, komposer kelompok Wayang Sampah. Alamat Mojosongo, Surakarta.

Muhammad Sulthoni (Toni Konde) 42 tahun, penggagas komunitas Wayang Sampah. Alamat Mojosongo, Surakarta. 